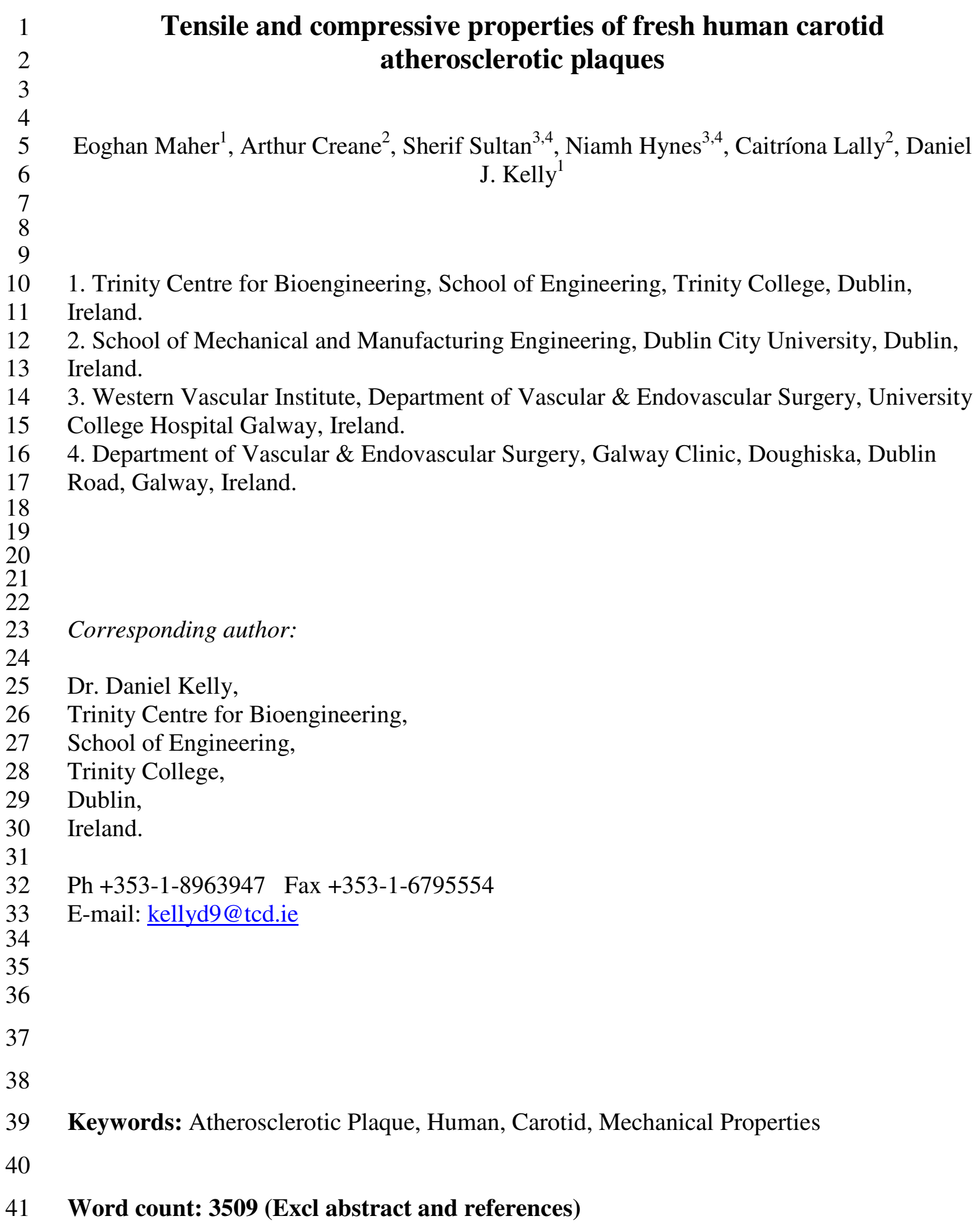

41 Word count: 3509 (Excl abstract and references)

\section{Tensile and compressive properties of fresh human carotid atherosclerotic plaques}

\author{
Eoghan Maher ${ }^{1}$, Arthur Creane ${ }^{2}$, Sherif Sultan ${ }^{3,4}$, Niamh Hynes ${ }^{3,4}$, Caitríona Lally ${ }^{2}$, Daniel \\ J. Kelly ${ }^{1}$
}

1. Trinity Centre for Bioengineering, School of Engineering, Trinity College, Dublin, Ireland.

2. School of Mechanical and Manufacturing Engineering, Dublin City University, Dublin, Ireland.

3. Western Vascular Institute, Department of Vascular \& Endovascular Surgery, University College Hospital Galway, Ireland.

4. Department of Vascular \& Endovascular Surgery, Galway Clinic, Doughiska, Dublin Road, Galway, Ireland.

Corresponding author:

Dr. Daniel Kelly,

Trinity Centre for Bioengineering, School of Engineering,

Trinity College,

Dublin,

Ireland.

$\mathrm{Ph}+353-1-8963947 \quad$ Fax +353-1-6795554

E-mail: kellyd9@tcd.ie

Keywords: Atherosclerotic Plaque, Human, Carotid, Mechanical Properties 


\section{Abstract}

4 Accurate characterisation of the mechanical properties of human atherosclerotic plaque is

5 important for our understanding of the role of vascular mechanics in the development and

6 treatment of atherosclerosis. The majority of previous studies investigating the mechanical

7 properties of human plaque are based on tests of plaque tissue removed following autopsy.

8 This study aims to characterise the mechanical behaviour of fresh human carotid plaques

9 removed during endarterectomy and tested within 2 hours. A total of 50 radial compressive

10 and 17 circumferential tensile uniaxial tests were performed on samples taken from 14

11 carotid plaques. The clinical classification of each plaque, as determined by duplex

12 ultrasound is also reported. Plaques were classified as calcified, mixed or echolucent.

13 Experimental data indicated that plaques were highly inhomogeneous; with variations seen

14 in the mechanical properties of plaque obtained from individual donors and between

15 donors. The mean behaviour of samples for each classification indicated that calcified

16 plaques had the stiffest response, while echolucent plaques were the least stiff. Results also

17 indicated that there may be a difference in behaviour of samples taken from different

18 anatomical locations (common, internal and external carotid), however the large variability

19 indicates that more testing is needed to reach significant conclusions. This work represents

20 a step towards a better understanding of the in vivo mechanical behaviour of human

21 atherosclerotic plaque. 


\section{Introduction}

2 Myocardial infarction and stroke are acute pathological events that occur during the chronic

3 process of atherosclerosis (Newby, 2005). Rupture or erosion of the artherosclerotic plaque,

4 and the subsequent thrombosis that results in occlusion or embolisation, are the two main

5 mechanisms involved in such conditions (Davies, 2000). While biomechanical forces have

6 been implicated in plaque fatigue and rupture (Cheng et al., 1993; Ku and McCord, 1993;

7 Loree et al., 1992; Richardson et al., 1989), such stimuli are also thought to play a major

8 role in the modelling and remodelling of such plaques (Glagov et al., 1997).

9 Atherosclerotic plaques contain $\mathrm{T}$ cells and lipid-laden macrophages (foam cells), which

10 are derived from blood monocytes (Libby, 1995). T cells produce factors which suppress

11 the production of collagen by the smooth muscle cells (SMCs) and stimulate macrophages

12 to produce matrix metalloproteinases (MMPs) which digest the existing collagen and other

13 extracellular matrix components (Nicolaides et al., 2002). The SMCs within the vessel wall,

14 which play a key role in maintaining the structural integrity of the plaque cap (Geng et al.,

15 1997; Seshiah et al., 2002), are influenced by the level of mechanical stretch they

16 experience (Sotoudeh et al., 2002). This may explain why regions of high strain in

17 artherosclerotic plaques correlate with low levels of SMCs (Schaar et al., 2003). These and

18 other studies confirm that vascular tissue mechanics and biology are intrinsically related in

19 the pathogenesis of atherosclerosis.

20 A complete understanding of the mechanics of diseased arteries is also critical to

21 optimising the outcomes of interventional procedures such as angioplasty and stenting. This

22 has enabled computational tools such as finite element models to be used in the

23 optimization of stent design. Early models focussed on the expansion characteristics of

24 balloon expandable (Chua et al., 2003; Dumoulin and Cochelin, 2000; Etave et al., 2001; 
1 Migliavacca et al., 2002; Petrini et al., 2004; Tan et al., 2001) and self expanding stent

2 designs (Whitcher, 1997). The necessity to understand both lumen gain and vessel injury

3 post-stenting has led to greater interest in modelling stent-plaque-artery interactions

4 (Auricchio et al., 2001; Bedoya et al., 2006; Chua et al., 2004; Early et al., 2009; Lally et

5 al., 2005; Migliavacca et al., 2004; Rogers et al., 1999). Further studies using anisotropic

6 constitutive equations for the artery wall (Holzapfel et al., (2002) have been performed for

7 both stenting (Kiousis et al., 2007) and for angioplasty (Gasser and Holzapfel, 2007). As

8 well as aiding the optimisation of stenting procedures, an increased understanding of the

9 mechanical properties of atherosclerotic tissue might be useful in the planning and

10 optimisation of surgical procedures. For example, prior knowledge of the properties of a

11 carotid plaque could inform the decision on whether to stent or perform an endarterectomy,

12 a surgical procedure to remove atherosclerotic plaque material from an artery by separating

13 the plaque from the arterial wall.

14 Our understanding of the role of vascular mechanics in all aspects of

15 atherosclerosis, from its development to its treatment, is impeded by insufficient

16 experimental data for diseased human tissue. The majority of experimental investigations of

17 atherosclerotic plaques are performed on cadaveric tissue. Lee et al (1991) dynamically

18 tested the fibrous cap of abdominal aortic plaques in radial compression and related their

19 findings to the cap composition as determined by histology. It was found that hypocellular

20 caps were 1-2 times stiffer than cellular and calcified were 4-5 times as stiff. In a further

21 study Lee et al (1992) performed radial compression relaxation tests on abdominal aortic

22 plaque caps. These results were compared to classifications from intravascular ultrasound

23 imaging and it was found that non-fibrous plaque caps had the lowest static stiffness and

24 longest relaxation time, calcified caps had the highest stiffness and lowest relaxation times 
1 and fibrous caps had values in between the other classifications. In contrast, Loree et al

2 (1994) found no significant difference between the static circumferential tangential moduli

3 of hypocellular, cellular and calcified plaques. Topelski et al (1997) investigated cyclic

4 compressive behaviour in aortoiliac plaques. Three types of plaque behaviour were

5 identified and related to results from histology. Salunke et al (2001) studied the

6 compressive stress relaxation behaviour of aortoiliac plaques when subjected to successive

7 stress relaxation tests and compared the results to histology and to similar tests on healthy

8 vessels. They found that during the loading cycle up to $25 \%$ compressive stretch that

9 calcified and fibrous plaques behaved similarly and that both were stiffer than atheromatous

10 plaques. The anisotropic behaviour of diseased iliac arteries was investigated by Holzapfel

11 et al. (2004). Each artery specimen was separated into its different artery and plaque

12 component layers, as determined by high resolution MRI. All the studies mentioned above

13 have been performed on cadaveric material. Given the delay before autopsy, and the fact

14 that there can be changes to soft tissue properties during short term storage (Stemper et al.,

15 2007), there is a need to obtain data for fresh human tissue.

16 The objective of this study is to determine the mechanical properties of fresh (tested

17 in less than 2 hours) carotid plaques following removal during endarterectomy. For this

18 purpose uniaxial circumferential tension and radial compression tests were performed on

19 plaque samples. This study also investigates in-patient variability and inter-patient

20 variability between specimens and the relationship between plaque properties and their

21 clinical classification and the location of the sample in the carotid bifurcation. 


\section{2. Materials and Methods}

2 Tensile and compressive tests were performed on samples taken from plaques of the carotid

3 bifurcation. Plaque specimens were removed from 14 patients ( 9 men and 5 women, $467 \pm 8.84 \mathrm{yrs}$, mean $\pm \mathrm{SD}$ ) during routine carotid endarterectomies. All surgeries and tests

5 were performed in the Galway Clinic, Ireland. The study includes 44 compressive and 16

6 tensile samples obtained from 14 carotid plaques. Table 1 includes all patient and lesion

7 details. Plaque classifications were determined independently by a clinician using routine

8 Duplex ultrasound with grey scale imaging (Nicolaides et al.; Tegos et al., 2001). Ethical 9 approval for testing of the human tissue was obtained.

\subsection{Sample Preparation}

12 Plaque specimens were prepared for testing immediately following removal in surgery.

13 Specimens were dissected at the bifurcation, separating them into common, internal and

14 external carotid segments, see figure 1. Each segment was opened by cutting along the axial

15 direction. Circumferential tensile and radial compressive samples were removed from each

16 of the flat rectangular segments using stainless steel punches. Dog-bone shaped tensile

17 samples were used which had a gauge length and width of $4 \mathrm{~mm}$ and $1 \mathrm{~mm}$ respectively.

18 Regions were deemed suitable for tensile testing if a sample with relatively consistent

19 composition could be obtained within the gauge length of the dog-bone sample. Due to the

20 small diameter of the external carotid, no tensile samples were obtained from these plaque

21 segments. $4 \mathrm{~mm}$ diameter compressive samples were also removed from the specimen.

22 Testing samples were allowed to equilibrate in $0.9 \%$ saline solution for approximately 30

23 minutes before measurements of the sample dimensions were recorded. 
2 Testing was performed using a computer controlled, high precision testing device adapted

3 for testing biological specimens (Bose ElectroForce 3100, Bose Corporation, Gillingham,

4 UK). The testing rig has an electromagnetic driven motor, with a stroke resolution of

$50.0015 \mathrm{~mm}$, a maximum stroke length of $5 \mathrm{~mm}$ and a minimum load resolution of $6 \mathrm{mN}$

6 with the $22 \mathrm{~N}$ load cell. Screw-based compressive platens and tensile grips were used during

7 testing, and the ability to interchange these allowed the same device to be used for both

8 compressive and tensile testing. All samples were stored in $0.9 \%$ saline solution until

9 testing. All samples were tested within two hours of harvesting.

10 Unconfined compression tests were performed on the $4 \mathrm{~mm}$ diameter compressive

11 samples. A sample was placed on the lower platen and the upper platen was moved to apply

12 a small compressive pre-load of $0.01 \mathrm{~N}$ to the sample at a crosshead speed of $0.001 \mathrm{~mm} / \mathrm{s}$.

13 This ensured a consistent contact between the platen and the top of the sample and minimal

14 strain in the plaque, $<5 \%$ in all cases. The sample height was then taken as the distance

15 between the platens at this pre-load. Before testing, preconditioning was achieved by

16 performing 10 loading and unloading cycles to $10 \%$ strain at a constant crosshead rate of

$171 \%$ strain/s. After preconditioning the sample was compressed at the same rate (1\%/s) until

$1860 \%$ strain was reached.

19 For tensile testing, a fast drying permanent marker was used to draw two parallel

20 horizontal lines across the gauge of the samples before testing. The tabs of a dog-bone

21 sample were then clamped in the tensile grips. The tensile grips were lined with sandpaper

22 in order to minimize sample slip within the grips. A tensile preload of $0.01 \mathrm{~N}$ was applied

23 to the sample at a rate of $0.001 \mathrm{~mm} / \mathrm{s}$ in order to ensure that the true gauge length was

24 measured. The preload caused only minimal strain in all samples $(<5 \%)$. During the tensile 
1 tests strain measurements were taken using a computer based video extensometer. The

2 extensometer automatically recognised marks and edges, and the gauge length after preload

3 and deformation between the gauge marks during testing was recorded by the computer.

4 Before testing the sample thickness was also measured using the video extensometer.

5 Similar preconditioning as with the compressive samples was applied to the tensile sample

6 after which the sample was stretched at a constant rate of $1 \%$ strain/s until the maximum

7 stretch allowed by the stroke length of the testing device was reached or until failure 8 occurred in the sample.

\subsection{Data Fitting and Analysis}

13 A $2^{\text {nd }}$ order isotropic hyperelastic model (Eqn. 1) was used to fit to the obtained 14 experimental data in this study. A general $2^{\text {nd }}$ order polynomial hyperelastic strain energy 15 function can be defined in terms of the strain invariants as follows (Abaqus Inc):

16

$$
\psi=C_{10}\left(I_{1}-3\right)+C_{01}\left(I_{2}-3\right)+C_{20}\left(I_{1}-3\right)^{2}+C_{11}\left(I_{1}-3\right)\left(I_{2}-3\right)+C_{02}\left(I_{2}-3\right)^{2}
$$

19 where $\psi$ is the strain energy function, $C_{\mathrm{ij}}, i+j=1,2$ are material constants and $I_{1}$ and $I_{2}$ are

20 the principle strain invariants. The strain invariants can be expressed in terms of the

21 principle stretches as $I_{1}=\lambda_{1}{ }^{2}+\lambda_{2}{ }^{2}+\lambda_{3}{ }^{2}$, and $I_{2}=\lambda_{1}{ }^{2} \lambda_{2}{ }^{2}+\lambda_{1}{ }^{2} \lambda_{3}{ }^{2}+\lambda_{2}{ }^{2} \lambda_{3}{ }^{2}$. For the case of 22 uniaxial testing of an incompressible material the nominal stress is given by: 


$$
T=\frac{\partial \psi}{\partial \lambda}=2\left(1-\lambda^{-3}\right)\left(\lambda \frac{\partial \psi}{\partial I_{1}}+\frac{\partial \psi}{\partial I_{2}}\right)
$$

3 where $\lambda$ is the stretch in the loading direction. Data fitting was performed using the test data 4 curve fitting function of the finite element package Abaqus 6.7-1, which uses a linear least

5 squares procedure to obtain the constants $C_{\mathrm{ij}}, i+j=1,2$. This method aims to minimize the 6 difference in nominal stress between the experimental test data and the data calculated from 7 Eqn. 2. The relative error, $E$, between these two values is given by Eqn. 3.

$$
E=\sum_{i}\left[1-\frac{\text { data measured }(i)}{\text { data calculated }(i)}\right]^{2}
$$

11 It is important to ensure that the constants obtained using this method lead to a stable

12 function. This is done by ensuring that the curves produced are positive definite. Stability 13 checking is done automatically in Abaqus when performing a curve fit. Where an unstable 14 curve is produced the constants are modified to produce a stable response. error measure $\zeta$, which is based on the sum of the square error between calculated and 17 measured data, is used (Eqn. 4). 
1 where $n$ is the number of data points and $q$ is the number of strain-energy function

2 constants. The value $T_{r e f}$ is the sum of all nominal stresses for each data point divided by

3 the number of data points.

4 The compressive data was analysed using a number of different criteria: (1) in-

5 patient variation; (2) inter-patient variation; (3) plaque classification; (4) sample location.

6 However due to the significantly lower number of tensile samples, tensile data was

7 analysed and presented together. All the stress strain data is graphed as nominal stress

8 against nominal strain. As the stress strain curves of the material approach failure the

9 curves, in some cases, become noisy. As a result of this a $10 \%$ drop in the stress as the

10 strain increases was viewed as material failure here, and the data wasn't analysed or

11 graphed following such a drop.

\section{3. Results}

15 Significant in-specimen variation in the compressive behaviour of human atherosclerotic 16 plaque was observed, see Fig. 2. For certain specimens, most notably specimens 2, 7 and 9,

17 there is a large amount of variation between samples. However for other specimens $(1,4$, 18 and 5) a much lower degree of variation was observed. When comparing the variation seen 19 to the clinical classification there appears to be no direct link between plaque classification 20 and in-specimen variation; for example specimen 4 is a mixed plaque but has low variation

21 while specimen 2 is also mixed but has a higher variability. When plaques were grouped by

22 clinical classification, a large amount of variability in the compressive behaviour for both

23 the calcified and mixed plaque specimens was observed, see Fig. 3. This variability is less

24 evident for the echolucent samples. Comparing the mean curves for each classification 
1 suggested that calcified samples were on average over twice as stiff as the echolucent

2 samples and 1.5-2 times stiffer than the mixed plaque. Large variations are also observed in

3 the compressive properties of samples taken from the same vessel section (either common,

4 internal and external) of the plaque, see Fig. 4. The average curve for each plaque location

5 does suggest some variation, with the common artery being the stiffest and the external the

6 least stiff; however no firm conclusions can yet be made about differences in plaques

7 between the three carotid vessels.

8 Significant variability was also observed in the tensile properties of fresh human

9 carotid plaque, see Fig. 5. Due to the smaller number of tensile samples, the main

10 conclusion that can be drawn from the tensile data is that there appears to be high

11 variability, both inter-specimen and in-specimen, in the tensile behaviour of these plaques.

12 The overall mean material constants obtained from curve fitting the compressive

13 and tensile data to a Mooney-Rivlin model are given in Table 2 and 3 respectively. These

14 tables also include information on the mean values for each of the constants obtained from

15 compressive testing for both the samples described by plaque classification and those

16 described by vessel. In the case of tensile data only the overall mean and standard deviation

17 (SD) are reported due to the lower number of samples tested.

\section{4. Discussion}

21 Improved understanding of the mechanical properties of diseased human carotid tissue may

22 enhance our understanding of the pathophysiology of atherosclerosis. Rupture and errosion

23 of such plaques are key mechanisms responsible for the development of cerebrovascular

24 events, which are related to the stress levels within the plaque cap. In this study the entire 
1 plaque is surgically separated from the artery during endarterectomy. This provided an

2 insight into how the plaque as a whole behaved and also enabled comparison to results

3 from ultrasound imaging with grey scale median values (US/GSM). The imaging technique

4 used here differs from previous studies: Lee et al (1992) used intravascular ultrasound

5 imaging; Holzapfel et al (2004) used hrMRI and histology, while numerous other studies

6 have used only histology. The choice of using US/GSM imaging was made as it is a non-

7 invasive imaging technique that is used routinely in the clinic to determine the optimum

8 treatment. This choice of imaging also enabled imaging to be performed before the surgery,

9 which helped reduce the time between plaque removal and completion of sample testing.

10 The plaque was assumed to behave as an isotropic hyperelastic material. The isotropic

11 material assumption was made as tests were only carried out in circumferential tension and

12 in radial compression for the specimens due to the constraint of the size of the plaque

13 specimens. While an anisotropic model has been used for other soft tissues such as artery

14 walls (Holzapfel et al., 2002), the high in-specimen inhomogeneity of the plaques may lead

15 to difficulties in modelling a consistent anisotropic behaviour.

16 The samples tested in this study generally show a non-linear behaviour during both

17 compressive and tensile testing. The non-linear behaviour of plaque tissue has been

18 demonstrated in previous studies (Salunke et al., 2001; Topelski et al., 1997); the one

19 exception to this nonlinear behaviour known to the authors was reported by Holzapfel et al

20 (2004) who reported that calcified tissue behaves almost linearly elastically. This was in

21 contrast to findings in this study as well as others (Loree et al., 1994; Salunke et al., 2001)

22 which generally found non-linear behaviour when testing tissue classified as calcified.

23 While variability between different plaque specimens has been reported before in the

24 literature (Holzapfel et al., 2004), there appears to be no data available on the in-specimen 
1 variations seen in the specimens in this study. The in-specimen variation observed in this

2 study suggests that much more localised mechanical testing needs to be performed.

3 Correlation of such data with in vivo imaging of a higher definition than US/GSM currently

4 provides is also necessary.

5 The inter-patient variability observed in this study provides further support for

6 patient (or lesion) specific stenting (Pericevic et al., 2009). The high variability between the

7 behaviour of different samples would seem to suggest that one stent design may be better

8 suited to a specific lesion than another; and the fact that there seems to be a relationship

9 between the average behaviour of the artery and the classification from the imaging, it may

10 be possible to use US/GSM to better inform the decision regarding the optimum stent

11 design. As anticipated, calcified plaques are on average stiffer than the other plaque types

12 (Figure 3). This was also reported by Holzapfel et al. (2004), however Salunke et al (2001)

13 found that there was no significant difference between calcified and fibrous plaques. No

14 definitive conclusion could be drawn from our study regarding the anatomical location of

15 the samples (Figure 4). Whilst the average curves seem to indicate that plaque segments in

16 the common carotid are stiffer than in the internal or external; the large variability means

17 that more testing is required in order for a more definitive conclusion to be reached.

18 There are a few limitations to the analyses performed in this study. The number of 19 samples, particularly with tensile data, limits the conclusions that may be drawn. The main

20 reason for the limited number of tensile samples is that the samples can be relatively large

21 with respect to the total plaque size and given the in-specimen plaque variability the authors

22 had some difficulty in obtaining samples with a relatively consistent material composition

23 within the gauge. While the largest sample size possible was used for these tensile tests, the

$244 \times 1 \mathrm{~mm}$ gauge length may be insufficient to fully prevent edge effects from the clamps. 
1 The tests were also unable to consistently produce failure of the tensile samples, this

2 resulted in not being able to report failure stresses and stretches for this study. However the

3 lack of fresh tissue data as well as the lack of data from human diseased carotid arteries

4 means this data may serve as a basis for constitutive equations used in finite element

5 modelling, with particular relevance to models of carotid lesions. The data can therefore be

6 seen as a basis for predicting outcomes of surgical and interventional procedures using

7 finite element modelling. Once a plaque has been classified in vivo the mean values of the

8 hyperelastic constants, as well as the upper and lower bound values of each constant, could

9 be used to predict a range of tissue responses that could be expected for a given procedure

10 or intervention. Whether the large standard deviations reported in this study actually

11 indicates large patient-to-patient variability in plaque properties that needs to be considered

12 in all computational models, or is merely a consequence of significant variability in the

13 properties of any given plaque and the sampling used in this study, needs to be further

14 investigated using more localised testing. This could possibly be achieved using indentation

15 testing (Barrett et al., 2009). Furthermore higher resolution imaging, which has previously

16 been used to detect the presence of stress rising microcalcifications in plaque fibrous caps

17 (Vengrenyuk et al., 2006), could be used to better characterise the heterogeneous nature of 18 plaque material.

19 In conclusion, this study characterised the radial compressive and circumferential

20 tensile behaviour of fresh carotid atherosclerotic plaques in order to obtain a better

21 understanding of plaque behaviour. The study also aimed to relate these results to imaging

22 which is used clinically to determine if treatment of a lesion is necessary thus giving the

23 results a more applicable clinical significance. It was seen that plaque classifications

24 obtained through US/GSM may be related to the mean behaviour of a lesion. This study 
1 represents a step toward better understanding of carotid plaque behaviour; it's relation to its

2 composition and the further use of finite element modelling in stent design. This data would

3 be important in order to obtain an accurate simulation of interventions such as stent

4 expansion or balloon angioplasty that consider lumen gain, vessel stresses and other factors

5 within the carotid artery. Such simulations could be used clinically to help decide between

6 different treatment options such as stenting and endarterectomy.

9 Acknowledgments

10 This material is based upon works supported by the Science Foundation Ireland under

\section{Grant No. 07/RFP /ENMF660.}

12

13

14

15

16

17

18

19

20

21

22

23

24

25 


\section{References}

AbaqusInc, Mechanical Constitutive Theories Abaqus Theory Manual. Simulia, Abaqus Version 6.7 Documentation.

Auricchio, F., Di Loreto, M., Sacco, E., 2001. Finite-element Analysis of a Stenotic Artery Revascularization Through a Stent Insertion. Computer Methods in Biomechanics and Biomedical Engineering, 4, 249-263.

Barrett, S.R., Sutcliffe, M.P., Howarth, S., Li, Z.Y., Gillard, J.H., 2009. Experimental measurement of the mechanical properties of carotid atherothrombotic plaque fibrous cap. J Biomech. doi:10.1016/j.jbiomech.2009.04.025.

Bedoya, J., Meyer, C., Timmins, L.H., Moreno, M.R., Moore, J.E., 2006. Effects of Stent Design Parameters on Normal Artery Wall Mechanics. Journal of Biomechanical Engineering, 128, 757-765.

Cheng, G.C., Loree, H.M., Kamm, R.D., Fishbein, M.C., Lee, R.T., 1993. Distribution of circumferential stress in ruptured and stable atherosclerotic lesions: A structural analysis with histopathological correlation. Circulation, 87, 1179-1187.

Chua, S.N.D., Mac Donald, B.J., Hashmi, M.S.J., 2003. Finite element simulation of stent and balloon interaction. Journal of Materials Prcessing Technology, 143-144.

Chua, S.N.D., Mac Donald, B.J., Hashmi, M.S.J., 2004. Effects of varying slotted tube (stent) geometry on its expansion behaviour using finite element method. Journal of Materials Prcessing Technology, 155-156, 1764-1771.

Davies, M.J., 2000. The pathophysiology of acute coronary syndromes. Heart, 83, 361-366.

Dumoulin, C., Cochelin, B., 2000. Mechanical Behaviour modelling of balloon-expandable stents. Journal of Biomechanics, 33, 1461-1470.

Early, M., Lally, C., Prendergast, P.J., Kelly, D.J., 2009. Stresses in peripheral arteries following stent placement: a finite element analysis Computer Methods in Biomechanics and Biomedical Engineering, 12, 25-33.

Etave, F., Finet, G., Boivin, G., Boyer, J.-C., Rioufol, G., Thollet, G., 2001. Mechanical properties of coronary stents determined by using finite element analysis. Journal of Biomechanics, 34, 1065-1075.

Gasser, T.C., Holzapfel, G.A., 2007. Modeling Plaque Fissuring and Dissection during Balloon Angioplasty Intervention. Annals of Biomedical Engineering, 35, 711-723.

Geng, Y.J., Henderson, L.E., Levesque, E.B., Muszynski, M., Libby, P., 1997. Fas is expressed in human atherosclerotic intima and promotes apoptosis of cytokineprimed human vascular smooth muscle cells. Arteriosclerosis, Thrombosis, and Vascular Biology, 17, 2200-2208.

Glagov, S., Bassiouny, H.S., Sakaguchi, Y., Goudet, C.A., Vito, R.P., 1997. Mechanical determinants of plaque modeling, remodeling and disruption. Atherosclerosis, 131, S13-S14.

Holzapfel, G.A., Sommer, G., Regitnig, P., 2004. Anisotropic Mechanical Properties of Tissue Components in Human Atherosclerotic Plaques. journal of Biomechanical Engineering, 126, 657-665.

Holzapfel, G.A., Stadler, M., Schulze-Bauer, C.A.J., 2002. A Layer-Specific ThreeDimensional Model for the Simulation of Balloon Angioplasty using Magnetic Resonance Imaging and Mechanical Testing. Annals of Biomedical Engineering, 30, 753-767. 
Kiousis, D.E., Gasser, T.C., Holzapfel, G.A., 2007. A Numerical Model to Study the Interaction of Vascular Stents with Human Atherosclerotic Lesions. Annals of Biomedical Engineering, 35, 1857-1869.

Ku, D.N., McCord, B.N., 1993. Cyclic stress causes rupture of the atherosclerotic plaque cap. Circulation, 88, 1362.

Lally, C., Dolan, F., Prendergast, P.J., 2005. Cardiovascular stent design and vessel stresses:a finite element analysis. Journal of Biomechanics, 38, 1574-1581.

Lee, R.T., Grodinsky, A.J., Frank, E.H., 1991. Structure-Dependent Dynamic Mechanical Behavior of Fibrous Caps From Human Atherosclerotic Plaques. Circulation, 83, 1764-1770.

Lee, R.T., Richardson, S.G., Loree, H.M., Grodinsky, A.J., Gharib, S.A., Schoen, F.J., Pandian, N., 1992. Prediction of mechanical properties of human atherosclerotic tissue by high-frequency intravascular ultrasound imaging. An in vitro study. Arteriosclerosis, Thrombosis, and Vascular Biology, 12, 1-5.

Libby, P., 1995. Molecular bases of the acute coronary syndromes. Circulation, 91, 28442850.

Loree, H.M., Grodinsky, A.J., Park, S.Y., Gibson, L.J., Lee, R.T., 1994. Static circumferential tangential modulus of human atherosclerotic tissue. Journal of Biomechanics, 27, 195-204.

Loree, H.M., Kamm, R.D., Stringfellow, R.G., Lee, R.T., 1992. Effects of fibrous cap thickness on peak circumferential stress in model atherosclerotic vessels. Circulation Research, 71, 850-858.

Migliavacca, F., Petrini, L., Colombo, M., Auricchio, F., Pietrabissa, R., 2002. Mechanical behavior of coronary stents investigated through the finite element method. Journal of Biomechanics, 35, 803-811.

Migliavacca, F., Petrini, L., Massarotti, P., Schievano, S., Auricchio, F., Dubini, G., 2004. Stainless and shape memory alloy coronary stents: a computational study on the interaction with the vascular wall. Biomechanics and Modeling in Mechanobiology, 2, 205-217.

Newby, A.C., 2005. Dual role of matrix metalloproteinases (matrixins) in intimal thickening and atherosclerotic plaque rupture. Physiological Reviews, 85, 1-31.

Nicolaides, A.N., Kakkos, S.K., Griffin, M., Geroulakos, G., Bashardi, E., 2002. Ultrasound plaque characterisation, genetic markers and risks. Pathophysiology of Haemostasis and Thrombosis, 32, 371-377.

Pericevic, I., Lally, C., Toner, D., Kelly, D.J., 2009. The influence of plaque composition on underlying arterial wall stress during stent expansion: The case for lesionspecific stents. Medical Engineering and Physics, doi:10.1016/j.medengphy.2008.11.005.

Petrini, L., Migliavacca, F., Auricchio, F., Dubini, G., 2004. Numerical investigation of the intravascular coronary stent flexibility. Journal of Biomechanics, 37, 495-501.

Richardson, P.D., Davies, M.J., Born, G.V.R., 1989. Influence of plaque configuration and stress distribution on fissuring of coronary atherosclerotic plaques. Lancet, 2, 941944.

Rogers, C., Tseng, Y.D., Squire, J.C., Edelman, E.R., 1999. Balloon-Artery Interactions During Stent Placement : A Finite Element Analysis Approach to Pressure, Compliance, and Stent Design as Contributors to Vascular Injury. Circulation Research, 84, 378-383. 
Salunke, N.V., Topelski, L.D.T., Humphrey, J.D., Mergner, W.J., 2001. Compressive 


\section{List of Figures and Tables}

2 Figure 1: Intact carotid plaque specimen. Dotted white lines show where specimen was 3 separated into common (C), internal (Int) and External (Ext) carotid segments.

5 Figure 2: Inter-patient variability of compressive samples

7 Figure 3: Compressive properties of calcified, echolucent and mixed plaques. Average 8 curves for each clinical classification were obtained from the mean set of hyperelastic 9 constants (see table 2)

11 Figure 4: Anatomical variation of compressive samples. Average curves for each vessel 12 location were obtained from the mean set of hyperelastic constants (see table 2)

14 Figure 5: Tensile data for each of the carotid plaques tested.

16 Table 1: Patient/specimen details. M, male; F, female; T, total no. of samples for specimen;

17 C, sample from common segment of specimen; I, sample from internal segment of 18 specimen; E, sample from external segment of specimen. Plaque classifications were 19 determined by an independent clinician, who was blinded to the mechanical testing results, 20 based on routine ultrasound with grey scale median imaging.

22 Table 2: Strain energy constants for compression testing of plaque samples (MPa). M 23 mixed; Ca - calcified; E - echolucent; C - common carotid; I - internal carotid; Ex 24 external carotid. 
2 Table 3: Strain energy constants for tension testing of plaque samples (MPa). M- mixed;

3 Ca - calcified; E - echolucent; C - common carotid; I - internal carotid; Ex - external 4 carotid.

5

6

7

8

9

10

11

12

13

14

15

16

17

18 


\section{Tables}

Table 1: Patient/specimen details

\begin{tabular}{|c|c|c|c|c|c|}
\hline Specimen & Gender & Age, yr & Clinical Classification & $\begin{array}{c}\text { No. of Compression } \\
\text { Samples }\end{array}$ & No. of Tensile Samples \\
\hline 1 & $\mathrm{M}$ & 67 & Mixed & $2 \mathrm{~T} ; 0 \mathrm{C} ; 2 \mathrm{I} ; 0 \mathrm{E}$ & $0 \mathrm{~T}$ \\
\hline 2 & M & 70 & Mixed & $5 \mathrm{~T} ; 2 \mathrm{C} ; 2 \mathrm{I} ; 1 \mathrm{E}$ & $0 \mathrm{~T}$ \\
\hline 3 & $\mathrm{~F}$ & 72 & Mixed & 3 T; 0 C; 3 I; 0 E & $2 \mathrm{~T} ; 2 \mathrm{C} ; 0 \mathrm{I}$ \\
\hline 4 & $\mathrm{~F}$ & 71 & Mixed & $4 \mathrm{~T} ; 1 \mathrm{C} ; 2 \mathrm{I} ; 1 \mathrm{E}$ & $1 \mathrm{~T} ; 1 \mathrm{C} ; 0 \mathrm{I}$ \\
\hline 5 & M & 51 & $\begin{array}{l}\text { Mixed(Lightly calcified) proximal } \\
\text { vessel, mostly echolucent at focal } \\
\text { plaque }\end{array}$ & $5 \mathrm{~T} ; 3 \mathrm{C} ; 1 \mathrm{I} ; 1 \mathrm{E}$ & $1 \mathrm{~T} ; 1 \mathrm{C} ; 0 \mathrm{I}$ \\
\hline 6 & M & 71 & Calcified proximally, mixed distally & $4 \mathrm{~T} ; 2 \mathrm{C} ; 1 \mathrm{I} ; 1 \mathrm{E}$ & $2 \mathrm{~T} ; 0 \mathrm{C} ; 2 \mathrm{I}$ \\
\hline 7 & M & 83 & Calcified Proximally, mixed distally & 7 T; 4 C; 2 I; 1 E & $0 \mathrm{~T}$ \\
\hline 8 & M & 73 & Calcified Proximally, mixed distally & $3 \mathrm{~T} ; 1 \mathrm{C} ; 1 \mathrm{I} ; 1 \mathrm{E}$ & $1 \mathrm{~T} ; 1 \mathrm{C} ; 0 \mathrm{I}$ \\
\hline 9 & $\mathrm{~F}$ & 78 & Calcified & $8 \mathrm{~T} ; 3 \mathrm{C} ; 3 \mathrm{I} ; 2 \mathrm{E}$ & $0 \mathrm{~T}$ \\
\hline 10 & M & 65 & Mixed & $0 \mathrm{~T}$ & $1 \mathrm{~T} ; 0 \mathrm{C} ; 1 \mathrm{I}$ \\
\hline 11 & M & 61 & Calcified & $1 \mathrm{~T} ; 0 \mathrm{C} ; 1 \mathrm{I} ; 0 \mathrm{E}$ & $1 \mathrm{~T} ; 1 \mathrm{C} ; 0 \mathrm{I}$ \\
\hline 12 & $\mathrm{~F}$ & 63 & Mostly calcified, echolucent at origin & $0 \mathrm{~T}$ & $3 \mathrm{~T} ; 3 \mathrm{C} ; 0$ I \\
\hline 13 & M & 58 & Mostly echolucent & 2 T; 0 C; 2 I; 0 E & $2 \mathrm{~T} ; 2 \mathrm{C} ; 0 \mathrm{I}$ \\
\hline \multirow{2}{*}{14} & $\mathrm{~F}$ & 55 & Calcified Proximally, mixed distally & $0 \mathrm{~T}$ & $2 \mathrm{~T} ; 2 \mathrm{C} ; 0 \mathrm{I}$ \\
\hline & $\begin{array}{c}\text { Age, } \\
\text { mean } \pm \text { SD } \\
y \mathrm{yr}\end{array}$ & $67 \pm 8.84$ & Total no. of Samples & $44 \mathrm{~T} ; 15 \mathrm{C} ; 20 \mathrm{I} ; 8 \mathrm{E}$ & $16 \mathrm{~T} ; 13 \mathrm{C} ; 3 \mathrm{I}$ \\
\hline
\end{tabular}

M, male; F, female; T, total no. of samples for specimen; C, sample from common segment of specimen; I, sample from internal segment of specimen; E, sample from external segment of specimen. Plaque classifications were determined by an independent clinician, who was blinded to the mechanical testing results, based on routine ultrasound with grey scale median imaging. 
Table 2: Strain energy constants for compression testing of plaque samples (MPa)

\begin{tabular}{|c|c|c|c|c|c|c|c|c|}
\hline Sample & Classification & Vessel & $\mathrm{C} 10$ & $\mathrm{C} 01$ & $\mathrm{C} 20$ & $\mathrm{C} 11$ & $\mathrm{C} 02$ & $\zeta$ \\
\hline 1 (i) & $\mathrm{M}$ & I & 0.042 & 0 & 0 & 0 & 0 & 0.0994 \\
\hline 1 (ii) & M & I & 0.0012 & 0.0208 & 0.0004 & 0 & 0 & 0.0971 \\
\hline 2 (i) & M & Ex & 0.0078 & 0 & 0 & 0 & 0 & 0.0996 \\
\hline 2 (ii) & M & I & 0.004 & -0.0009 & 0 & 0 & 0.000546 & 0.0924 \\
\hline 2 (iii) & M & $\mathrm{C}$ & 0.07 & 0.041 & 0.126 & 0.009 & 0 & 0.098 \\
\hline 2 (iv) & M & $\mathrm{C}$ & 0.001468 & 0.0013 & 0.00012 & 0 & 0.00012 & 0.0296 \\
\hline $2(\mathrm{v})$ & M & I & 0.001 & 0.053 & 0 & 0 & 0 & 0.0958 \\
\hline 3 (i) & M & I & 0.006 & 0.04 & 0.2 & 0 & 0 & 0.0693 \\
\hline 3 (ii) & M & I & 0.002 & 0.04 & 0.08 & 0 & 0 & 0.0992 \\
\hline 3 (iii) & M & I & 0.005 & 0.0019 & 0.0062 & 0.001 & 0 & 0.0883 \\
\hline 4 (i) & M & $\mathrm{C}$ & 0.001 & 0.00271 & 0 & 0 & 0 & 0.0894 \\
\hline 4 (ii) & M & I & 0.00868 & 0 & 0 & 0 & 0 & 0.0965 \\
\hline 4 (iii) & M & I & 0.0012 & 0 & 0 & 0 & 0 & 0.0873 \\
\hline 4 (iv) & M & Ex & 0.001 & 0.0012 & 0.0002 & 0 & 0 & 0.0964 \\
\hline 5 (i) & $\mathrm{E}$ & $\mathrm{C}$ & 0.0001 & 0.0164 & 0.0319 & 0 & 0 & 0.0955 \\
\hline 5 (ii) & $\mathrm{E}$ & $\mathrm{C}$ & 0.003 & 0.004 & 0.001 & 0.003 & 0 & 0.0955 \\
\hline 5 (iii) & M & $\mathrm{C}$ & 0.002 & 0.015 & 0.0195 & 0 & 0.001 & 0.086 \\
\hline 5 (iv) & M & I & 0.001 & 0.005 & 0.042 & -0.001 & 0.0086 & 0.0952 \\
\hline $5(\mathrm{v})$ & $\mathrm{E}$ & Ex & 0.00071 & 0 & 0 & 0 & 0 & 0.0985 \\
\hline 6 (i) & M & $\mathrm{C}$ & 0.001 & 0.00556 & 0 & 0 & 0 & 0.095 \\
\hline 6 (ii) & M & $\mathrm{C}$ & 0.0005 & 0.00237 & 0 & 0 & 0 & 0.0776 \\
\hline 6 (iii) & M & Ex & 0.001 & 0.00104 & 0 & 0 & 0 & 0.0869 \\
\hline 6 (iv) & M & I & 0.0016 & 0 & 0 & 0 & 0.00465 & 0.0283 \\
\hline 7 (i) & M & $\mathrm{C}$ & 0.0001 & 0 & 0 & 0 & 0.0031 & 0.0998 \\
\hline 7 (ii) & M & $\mathrm{C}$ & 0.0015 & 0 & 0 & 0 & 0 & 0.0858 \\
\hline 7 (iii) & $\mathrm{Ca}$ & $\mathrm{C}$ & 0.0001 & 0 & 0 & 0 & 0.1363 & 0.0996 \\
\hline 7 (iv) & $\mathrm{Ca}$ & $\mathrm{C}$ & 0.005 & 0.002 & 0.007 & 0.001 & 0 & 0.0974 \\
\hline $7(\mathrm{v})$ & $\mathrm{Ca}$ & I & 0.0102 & 0 & 0 & 0 & 0 & 0.0924 \\
\hline 7 (vi) & $\mathrm{Ca}$ & I & 0.001 & 0.012 & 0.004 & 0 & 0 & 0.0719 \\
\hline 7 (vii) & M & Ex & 0.0122 & 0 & 0 & 0 & 0 & 0.0998 \\
\hline $8(\mathrm{i})$ & $\mathrm{Ca}$ & $\mathrm{C}$ & 0.001 & 0.0019 & 0.1 & 0.004 & 0 & 0.071606 \\
\hline 8(ii) & $\mathrm{Ca}$ & I & 0.001 & 0.06 & 0.3 & 0.004 & 0 & 0.036145 \\
\hline 8(iii) & $\mathrm{Ca}$ & Ex & 0.001 & 0.001 & 0.1 & 0.01 & 0 & 0.005753 \\
\hline 9 (i) & $\mathrm{Ca}$ & $\mathrm{C}$ & 0.001 & 0.0275 & 0.1478 & 0 & 0 & 0.0973 \\
\hline 9 (ii) & $\mathrm{Ca}$ & $\mathrm{C}$ & -0.0325 & 0.106 & 1.275 & 0.935 & 0.1 & 0.0951 \\
\hline 9 (iii) & $\mathrm{Ca}$ & I & 0.002 & 0.005 & 0.12 & 0 & .002 & 0.0563 \\
\hline 9 (iv) & $\mathrm{Ca}$ & $\mathrm{C}$ & -0.005 & 0.034 & 0.0177 & 0 & 0 & 0.0908 \\
\hline $9(\mathrm{v})$ & $\mathrm{Ca}$ & I & 0.001 & 0.0012 & 0.0059 & 0 & 0 & 0.0637 \\
\hline $9(\mathrm{vi})$ & $\mathrm{Ca}$ & I & 0.014 & 0.0172 & 0.0948 & 0.181 & 0.038 & 0.0966 \\
\hline 9 (vii) & $\mathrm{Ca}$ & Ex & 0.001 & 0.001 & 0.025 & 0.0085 & 0 & 0.071606 \\
\hline 9 (viii) & $\mathrm{Ca}$ & Ex & 0.017 & 0.04 & 0.03 & 0 & 0 & 0.036145 \\
\hline 11 (i) & $\mathrm{Ca}$ & I & 0.0005 & 0 & 0 & 0 & 0.0395 & 0.005753 \\
\hline 13 (i) & E & I & 0.001 & 0.038 & 0 & 0 & 0 & 0.040922 \\
\hline 13(ii) & E & I & 0.001 & 0 & 0.01 & 0 & 0.0011 & 0.090544 \\
\hline Overall & Mean \pm SD & & $.00449 \pm 0.01354$ & $.01357 \pm 0.02203$ & $.06238 \pm 0.197495$ & $.02626 \pm 0.1428$ & $.00761 \pm 0.02603$ & $.0828 \pm 0.0227$ \\
\hline Calcified & Mean \pm SD & & $.001144 \pm 0.0106$ & $.0193 \pm 0.02929$ & $.1392 \pm 0.313344$ & $.07147 \pm 0.23459$ & $.01974 \pm 0.04111$ & $.0768 \pm 0.0261$ \\
\hline Mixed & Mean \pm SD & & $.00753 \pm 0.01616$ & $.00999 \pm 0.01669$ & $.02063 \pm 0.04985$ & $.00039 \pm 0.00205$ & $.00078 \pm 0.00205$ & $.0866 \pm 0.0197$ \\
\hline Echolucent & Mean \pm SD & & $.00116 \pm 0.00109$ & $.01168 \pm 0.01618$ & $.00858 \pm 0.013698$ & $.0006 \pm 0.001342$ & $.00022 \pm 0.00049$ & $.0842 \pm 0.0244$ \\
\hline Common & Mean \pm SD & & $.00314 \pm 0.01978$ & $.01623 \pm 0.02729$ & $.10768 \pm 0.315057$ & $.0595 \pm 0.233479$ & $.01503 \pm 0.04080$ & $.0873 \pm 0.0173$ \\
\hline Internal & Mean \pm SD & & $.00527 \pm 0.00941$ & $.01466 \pm 0.02011$ & $.04317 \pm 0.080941$ & $.00925 \pm 0.04044$ & $.00472 \pm 0.01183$ & $.0801 \pm 0.0226$ \\
\hline External & Mean \pm SD & & $0.0052 \pm 0.00639$ & $0.0055 \pm 0.01394$ & $0.0194 \pm 0.034876$ & $0.00231 \pm .0043$ & $0 \pm 0$ & $.0801 \pm .03236$ \\
\hline
\end{tabular}

M - mixed; Ca - calcified; E - echolucent; C - common carotid; I - internal carotid; Ex - external carotid 
Table 3: Strain energy constants for tension testing of plaque samples (MPa)

\begin{tabular}{ccccccccc}
\hline Sample & Classification & Vessel & C10 & C01 & C20 & C11 & C02 & $\zeta$ \\
\hline 3 (i) & M & C & 0.001 & 0.05 & 0.06 & 0.04 & 0 & 0.0674 \\
3 (ii) & M & C & 0.001 & 0.35 & 1.8 & 0.4 & 0.621 & 0.0967 \\
4 (i) & M & C & 0.015 & 0.0051 & 0.001 & 0.0006 & 0.011 & 0.0988 \\
5 (i) & E & C & 0.01 & 0.01 & 0.0159 & 0.09 & 0 & 0.0999 \\
6 (i) & $\mathrm{Ca}$ & $\mathrm{I}$ & 0.001 & 0.185 & 0.1 & 0.05 & 0.09 & 0.0969 \\
6 (ii) & $\mathrm{Ca}$ & $\mathrm{I}$ & 0.001 & 0 & 0.8 & 1.82 & 3.32 & 0.0995 \\
8 (i) & $\mathrm{Ca}$ & $\mathrm{C}$ & 0.1 & 0 & 0.2 & 0 & 0.106 & 0.09918 \\
10 (i) & $\mathrm{M}$ & $\mathrm{I}$ & 0.001 & 0 & 9.8 & 0 & 0 & 0.0986 \\
11 (i) & $\mathrm{Ca}$ & $\mathrm{C}$ & 0.001 & 0.01 & 0.03 & 0 & 0.07 & 0.0998 \\
12 (i) & $\mathrm{Ca}$ & $\mathrm{C}$ & 0.001 & 0.1 & 0.275 & -0.005 & 0.27 & 0.0503 \\
12 (ii) & $\mathrm{Ca}$ & $\mathrm{C}$ & 0.02 & 0.005 & -0.001 & 0.02 & 0.155 & 0.0989 \\
12 (iii) & $\mathrm{E}$ & $\mathrm{C}$ & 0.004 & -0.002 & -0.005 & 0.06 & 0.14 & 0.0994 \\
13 (i) & $\mathrm{E}$ & $\mathrm{C}$ & 0.02 & 0.01 & 0 & 0.03 & 0 & 0.0457 \\
13 (ii) & $\mathrm{E}$ & $\mathrm{C}$ & 0.048 & 0.069 & 0 & 0.061 & 0 & 0.0837 \\
14 (i) & $\mathrm{Ca}$ & $\mathrm{C}$ & 0.1 & .025 & 0 & 0.59 & 0 & 0.0547 \\
14 (ii) & $\mathrm{Ca}$ & $\mathrm{C}$ & 0.05 & 0 & 0 & 0.14 & 0.4 & 0.0992 \\
\hline Overall & Mean \pm SD & & $0.0234 \pm 0.0339$ & $0.0651 \pm 0.1061$ & $0.817 \pm 2.441$ & $0.206 \pm 0.4606$ & $0.324 \pm 0.8177$ & $0.0868 \pm 0.0201$
\end{tabular}

M - mixed; Ca - calcified; E - echolucent; C - common carotid; I - internal carotid; Ex - external carotid 


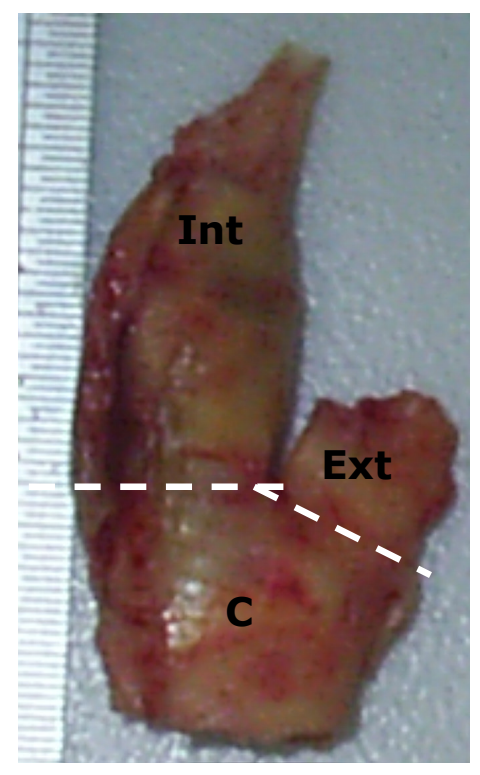



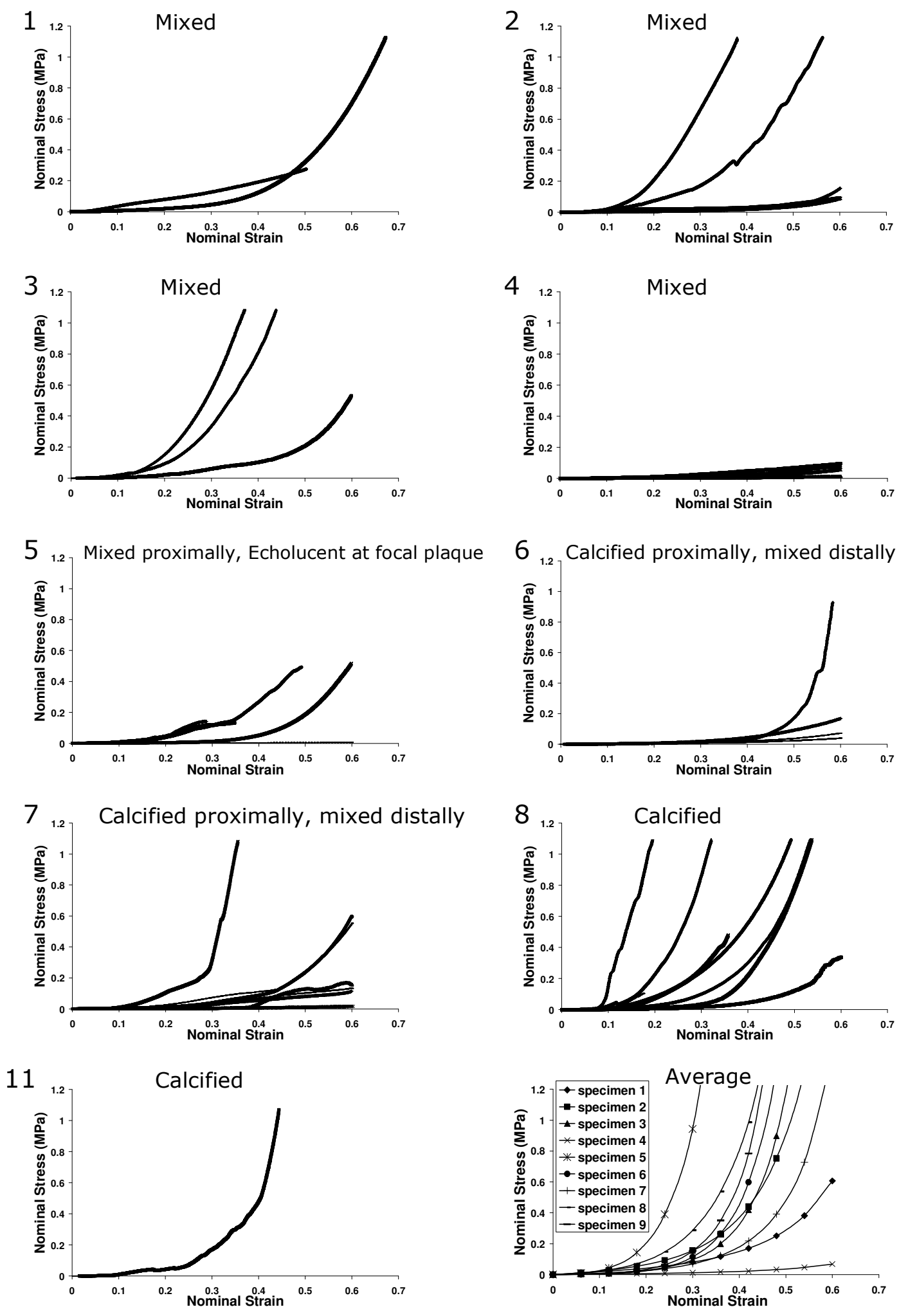

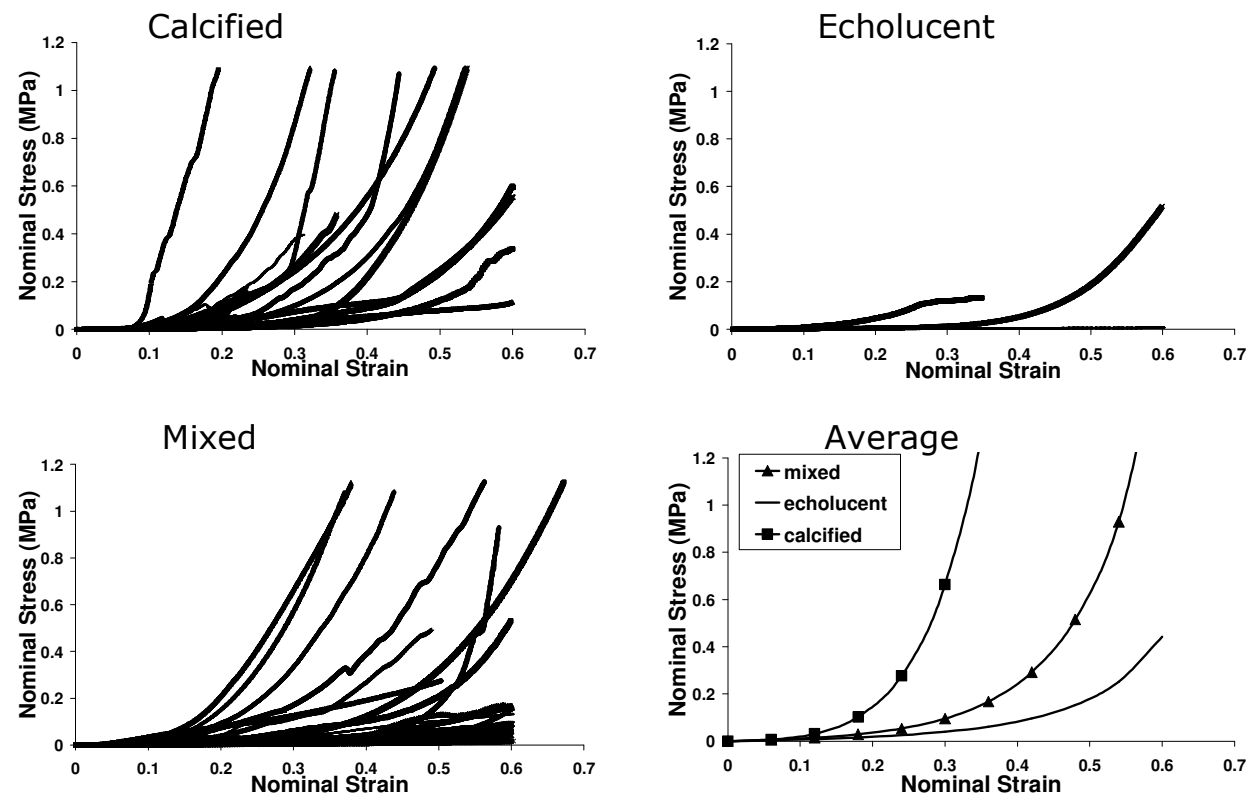

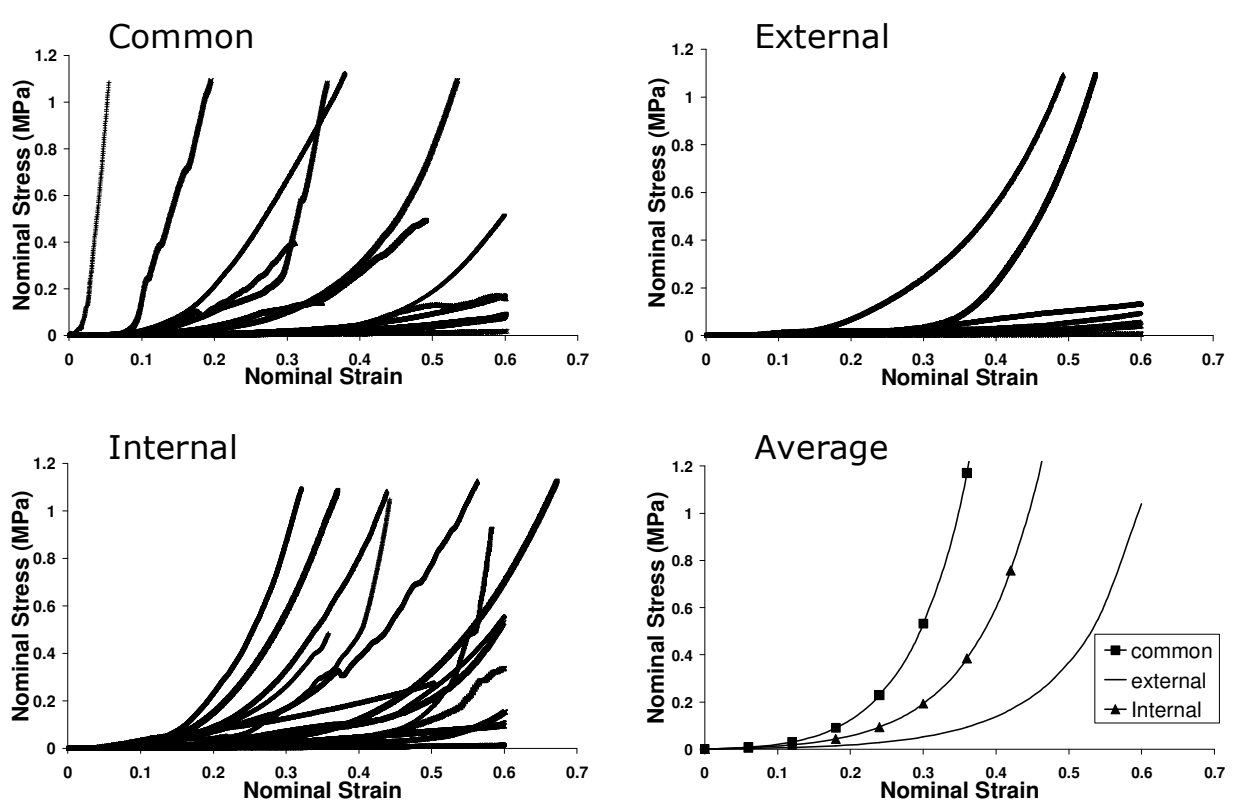


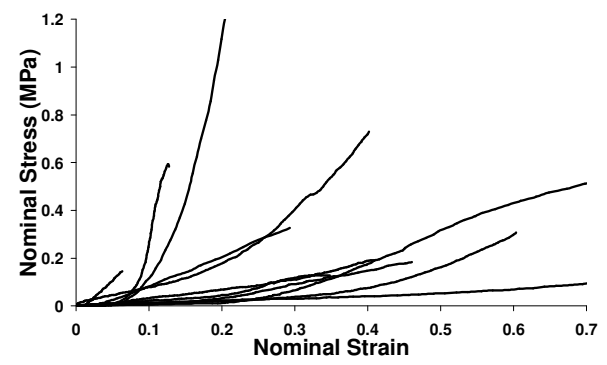

